\title{
Study on Singing Skills and Teaching Ideas in "July's Prairie"
}

\author{
Tong Chen, Kuaian Jiang \\ Guangdong University of Petrochemical Technology, Maoming, Guangdong, 525000
}

Keywords: "July's Prairie"; works analysis; singing skills; vocal music teaching

\begin{abstract}
July's Prairie" is a beautifully melodic and artistic conception of a flowery soprano work. It is one of the representative works of the composer, Shang Deyi's outstanding artistic songs. The work is full of Xinjiang's ethnic customs and shows the herdsmen's simple and beautiful life. It is widely spread, and the work is also one of the many soprano singers who must sing. As a singer and at the same time university teacher, the writer often sang and taught this work in practical singing and vocal music teaching, with a theoretical and practical understanding and experience of the work. Therefore, when studying this work, this paper focuses on the study of singing skills of the works and the teaching of the works in the vocal music classes. The author believes that to sing good works on the stage, good atmosphere control, solid flower cavity skills and the delicate expression of the internal emotions of the works are the most important three points in the technique of singing good works. In the process of teaching this work, in the vocal music teaching, it is necessary to pay attention to the division of the students' voice and the training of the flower pot skills, helpful for the future singing.
\end{abstract}

\section{Introduction}

"July's Prairie" consists of Song Binyan's lyrics and Shang Deyi's composition. It is a melodious, artistically rich, flowery soprano work, and one of the famous masterpieces of Mr. Shang Deyi. Looking at the data, we find that many domestic researchers are limited to the analysis and research of the music ontology of this work, most of which are concentrated in the following aspects: the musicality of the work, the linguistic literariness of the work, the musical structure of the work, works Piano accompaniment and so on. The articles that really involve singing skills and teaching ideas are rare. This article focuses on talking about singing skills and teaching. When Mr. Shang Deyi created the "Prairie of July", he combined the characteristics of foreign flower pots with the music of domestic folk styles. His works were full of distinctive ethnic styles, and they also had the skills of composing abroad. They had very high artistic value. After careful analysis of this work, we can understand Mr. Shang Deyi's artistic accomplishments and have a deep understanding of the melody rhythm and piano accompaniment of the work. It can also form an in-depth understanding of the theoretical knowledge related to flower cavity singing, and brings strong and solid support to singing in theory.

\section{Analysis of Singing Skills in "July's Prairie"}

The singing of the singer is a once more artistic representation of the creation of the work, and the expression of the artistic song is even more so. The singer's perfect concert is in tune with the song, otherwise it will leave the excellent vocal work blank. It is also necessary to create the second time even better. Strengthening the training of basic vocal music is one of the most basic and effective ways. Second, because the style of the work is different, the sound image required by the work is also inconsistent, and the required tone, breath, and language will be different. The author through his own singing experience, at the same time analysis of the domestic excellent soprano singing this work, that: want to sing good "July's Prairie", the following experience for reference.

The singer should understand the background of the song's creation, the emotion conveyed by the lyrics, the structure and characteristics of the melody, and so on, to pave the way for the use of breath, rhetoric, and reasonable transmission of emotions. In the singing of Huaqiang works, breath 
and biting are the two major difficulties. The lack of breath will make the high tone unstable. If it is too strong, it will weaken the effect of emotional expression. The lack of clear biting will bring word meaning to the audience. direct impact. The singer should adjust the breath to the best state at the beginning of the prelude, and should follow the changes of the lyrics and melody continuously to adjust again. When singing song A section, it requires flexibility and lightness, such as the "small" word in the "small honey" in the first sentence, which requires a clear and clean voice. When singing the words "Wengweng" and "aa" in the latter part of the sentence, pay attention to the lines of the notes. We need to pay attention to the continuity while we cannot lose the middle of the skipping, so that the sound is constantly off. A cut off the middle part of the main lyrical, we need to strengthen the breath, can freely use the breath, while paying attention to the breath and the wording while singing the national charm of the song out, enhance the rhythm of music. During the verse "Ah" in song B, you must not sing "e" or "o", open the inner mouth, lift the small tongue slightly, make a slight breath, and the sound should be smooth and smooth, so that the song is strong The penetrating power, singing a flowing, dexterous feeling.

The sound is wonderful again. Assuming that it is not adorned with genuine emotions, it will be bleak. In singing, the two elements of sound and emotion complement each other. In the singer's emotional singing, listeners will resonate deep within their hearts. The singers must understand the connotation of the song "July of the Grassland" and have the deep feelings of the grassland scenery and the herdsmen's life. They can show it vividly, sing their true feelings, and convey a lively and lively feeling to the audience. In addition, during the singing, we should think of the vast and untouchable grassland, where bees and butterflies flutter along the road, and Uighur men and girls race to the prairie. In this way, with the skillful use of flower cavity techniques, it is possible to precisely convey the praise for the prairie scenery and the people's good life, and love the feelings of the great motherland.

In vocal singing, singing techniques are of key significance. Skills are the precondition for art in the field of vocal music. We usually concentrate on practicing sound skills in the learning stage of the flower room and gradually neglect its essential and artistic features. In fact, singing was originally a method of conveying emotions and lyrics. However, as it gradually evolved into an art category, people usually neglected their original intentions. No matter what kind of singing techniques, the purpose is to demonstrate the vocal music singing art. The artistic beauty of the show is inseparable from the technology, but the display of the perfect art is inseparable from the exquisite techniques. Both are indispensable and complement each other. First, master its artistic characteristics in accordance with the diverse creative subjects. All composers have a unique creative style. For example, in Verdi's opera, the technique of flower cavity makes characters more individualized and filled with drama and melody. When singing his works, he should pay attention to portraying the inner delicate emotions of the characters and blending the emotion bursts with the power of drama. Second, master the artistic characteristics of Huadu in accordance with the diversity of song styles. For example, the works explored in this paper are full of joyful and lively rhythms. For this purpose, the songs should be sung with warm and cheerful full emotions. From a macro perspective, ethnic cultural thoughts vary from one era to another, and from a micro perspective, artistic appeal differs depending on the shape of the flower. We must exercise due certainty. Should not only focus on flower cavity techniques and ignore its art, otherwise the voice will be pale and powerless, and the artistic vitality cannot be sustained.

\section{Teaching Ideas "July's Prairie"}

"July's Prairie" is one of the most important soprano repertoires for solo artists. Soprano students often sing during the third year of senior high school. In the long-term vocal music teaching process, teachers often find that they want to sing good works of this kind. Not only is it simple, but beyond a certain degree of basic skills, the following vocal teaching ideas are also worth communicating with everyone. Through the study of "July's Prairie", the author found that it is very important for a singer to understand his own voice and master the art of flower pot.

Singing highly challenging vocal techniques requires a natural and relaxed singing style. Only a 
reasonable division of the vocal part can form this state. To make any kind of noise condition can be improved on the basis of the previous, it is necessary to tap the potential of natural singing, so as to avoid arranging good voice conditions due to unreasonable vocalization concepts. Regardless of the voice part, if you want to have perfect brooding skills, you must sing in the natural state with the timbre of natural conversation. Let mezzo-soprano perform soprano and soprano, it's more difficult to sing in high-pitched voices, and the performance of gorgeous flower-body techniques is even more so. Reasonable division of the voice is a prerequisite for natural singing. However, this problem seems easy, but many people have not paid attention.

The concept of "Hua Qiang” first came from abroad, which meant that the melody was exquisite and flexible. Nowadays, it often refers to the modification of vocal melody. It makes the whole process of singing as graceful, bright, and very demanding. Vocal skills cover many types of retouching sounds such as echo, boeing, vibrato, glissando, and sway.

At the beginning of the development of his skills, the singer only used the technique when he was showing off his skills. The era is constantly developing. The audience's pursuit is no longer confined to the singer's skill. In order to keep up with the times At the pace, singing should be more involved in the emotional expression factor, which in its singing, occupies a core component, making the song sound like heaven sounds. For this reason, flower cavity techniques are used as a form of vocal expression. This method displays complex, cheerful, or dramatic dramatic emotions. Under the support of this superb artistry, the singing art can better show its beauty and is influenced by the masses. Sought after.

The training of anabrosis techniques should be persevering, and with a certain singing purpose to advance gradually. In the popular stage of deaf singers, the technique of performing arts and crafts to maximize the use of skills, but the skills of the outstanding and the professional content of the study and diligent training are closely linked. Although limited to the physiological structure, they should learn from the way of learning when performing chanting techniques, and then resolve some of the difficulties during singing. For the difficulties in flower cavity training, the following description.

First, pitch problems in flower cavity technology. Treble as a major feature of flower cavity techniques. However, only super-high pitches can be easily acquired by some talented people. Most singers can only acquire them in a scientific manner and through long-term practice. According to the author's point of view, the ability to sing high notes depends on the high position and deep breathing. The latter seems simple, but there is a certain degree of difficulty in practice.

Second, the difficulty in flower cavity technology is the issue of training sound flexibility. Variety techniques such as fast scale up and down, Boeing, tremolo, arpeggio, and echo are contained in the flower cavity technique in a large number of hurried phrases and decorative sounds. However, such exquisite and colorful flowerpot techniques have a certain degree of flexibility, otherwise they lose their sense of beauty.

\section{Conclusion}

Singing training and learning is a gradual process. Any ideas and practices that are quick to gain instant success cannot be successful. This requires the singers to continue to learn and train until they strive for perfection. Most of the vocal soprano works are sensational, melodious, and high-pitched. They are highly sought after by the singers and are loved by the audience. This is particularly true in the "July of the Prairie". The songs, singing and teaching ideas of this song are studied and analyzed. It is concluded that to sing a good song must take sufficient time and effort, carefully analyze the composition of the work, the background of the song's creation, and the emotional expression of the song, grasp the delicate parts of it, and use very skillful The vocal arts skills are sang in emotions. To sing the song "July in the Steppe," it is necessary to have a certain foundation for vocal music singing, to have a good sounding state, to perform singing skills in flower pots, and to have an aesthetic pursuit that embodies Chinese music styles, using the academic language of the current vocal music industry. For her part, she is not only suitable for professional singing, but also suitable for national vocal professional singing. It is a representative 
song of the so-called "Chinese vocal school"!

\section{References}

[1] Zheng Cuixi. Creative characteristics and singing study of the song "July's Prairie" [J]. Journal of Ningde Teachers College, 2017.1.

[2] Lin Siming. Brief Analysis of the Artistic Features and Performance of the Song "July's Prairie"[J]. The Voice of the Yellow River.2016.7.

[3] Tian Zhuoyu. Musical characteristics and appreciation of piano accompaniment in the song "July's Prairie" [J]. Appreciation of Famous Works, 2013.8

[4] Liu Yanfang. On the musical characteristics of "July's Prairie" and its singing performance [J] stage, 2010.8.

[5] Yu Huicheng. "July's Prairie" singing analysis and processing [J]. Journal of Liaocheng University (Social Sciences Edition), 2010.2.

[6] Yan Xiaohui. The creative characteristics of the flower cavity art song "July's Prairie” [J]. Voice of the Yellow River, 2015.2

[7] Jin Aihua. The role of flower cavity techniques in opera singing [J]. Northern Music, 2006.3. 